\title{
Increased Use of Blood Transfusions to Manage Urological Conditions during the COVID-19 Pandemic
}

\author{
Paolo Capogrosso ${ }^{a}$ Luigi Candela ${ }^{b, c}$ Piercarlo Rossi ${ }^{a}$ Cristian Guarasci ${ }^{a}$ \\ Fabio Muttin $^{c, d}$ Marco Roscigno $^{d}$ Rosa Chianese $^{a, e}$ Luca Santoleri $^{b}$ \\ Michela Tassara $^{b}$ Giulio Carcano ${ }^{a, e}$ Richard Nasprod ${ }^{d}$ Luigi Da Pozzo $^{d, f}$ \\ Francesco Montorsi $^{\mathrm{b}, c}$ Andrea Salonia ${ }^{\mathrm{b}, \mathrm{c}}$ Federico Dehò ${ }^{\mathrm{a}, \mathrm{e}}$ \\ ${ }^{a}$ Department of Urology, Ospedale di Circolo e Fondazione Macchi - ASST Sette Laghi, Varese, Italy; ${ }^{\text {b Unit of }}$ \\ Urology, Division of Experimental Oncology, URI, IRCCS Ospedale San Raffaele, Milan, Italy; ${ }^{\circ}$ Vita-Salute San Raffaele \\ University, Milan, Italy; ${ }^{d}$ Department of Urology, Papa Giovanni XIII Hospital, Bergamo, Italy; ' University of Insubria, \\ Varese, Italy; ${ }^{f}$ University of Bicocca, Milan, Italy
}

\section{Keywords}

COVID-19 $\cdot$ Blood transfusion $\cdot$ Hematuria $\cdot$ Bleeding

\begin{abstract}
Introduction: Severe acute respiratory syndrome coronavirus 2 (SARS-CoV-2) led to an extensive reorganization of the healthcare system in Italy, with significant deferment of the treatment of urology patients. We aimed to assess the impact of deferred treatment during the SARS-CoV-2 pandemic on the need for blood transfusions in 3 Italian urology departments. Methods: We reviewed hospital chart data on blood transfusions at the urology units of 3 academic centers in the north of Italy from March to April 2020. Data were compared with values from the same time frame in 2019 (March to April 2019). Results: We observed significant reductions of the number of patients admitted to the urology units from March to April 2020 (373 vs. 119) and the number of performed surgeries (242 vs. 938) compared to 2019. Though, the number of transfused blood units was comparable between the 2 years (182 vs. 252), we found a greater mean
\end{abstract}

karger@karger.com

(c) 2020 S. Karger AG, Basel

www.karger.com/uin

Karger" number of blood units transfused per admission in 2020 $(0.49$ vs. $0.22 ; p<0.0001)$. As a whole, the transfusion rate for hematuria was higher in 2020 than in 2019 (36 vs. 7.9\%; $p<$ 0.0001). Discussion/Conclusion: The observed increased number of blood transfusions needed throughout the SARSCoV-2 era could have had a negative impact on both patients and the healthcare system. It is possible to speculate that this is the consequence of a delayed diagnosis and deferred treatment of acute conditions.

(c) 2020 S. Karger AG, Basel

\section{Introduction}

The new severe acute respiratory syndrome coronavirus 2 (SARS-CoV-2) pandemic struck Europe in the early months of 2020 . Italy is among the first and most affected countries, with a total of 224,760 laboratory-confirmed SARS-CoV-2 patients at the time this paper was written [1]. During the core of the pandemic, which was mainly from March to April 2020, the Italian National 
Table 1. Blood transfusions in the urology department of 2 Italian academic centers from March to April 2019 and from March to April 2020

\begin{tabular}{|c|c|c|c|}
\hline & March to April 2019 & March to April 2020 & $p$ value \\
\hline Admissions & 1,119 & 373 & - \\
\hline Surgeries & 938 & 242 & - \\
\hline Transfused blood units & 252 & 182 & - \\
\hline Blood units per admission, $n$ & $0.22 \pm 0.84$ & $0.49 \pm 1.62$ & $<0.0001$ \\
\hline \multicolumn{4}{|l|}{ Reason for transfusion ${ }^{1}$} \\
\hline Hematuria & $20(7.9)$ & $66(36)$ & $<0.0001$ \\
\hline Intra-/postoperative bleeding & $211(84)$ & $97(53)$ & \\
\hline Others & $21(8.3)$ & $19(10)$ & \\
\hline \multicolumn{4}{|l|}{ Underlying disease $^{1}$} \\
\hline Bladder cancer & $86(34)$ & $86(47)$ & 0.0002 \\
\hline Kidney cancer & $46(18)$ & $33(18)$ & \\
\hline Prostate cancer & $28(11)$ & $1(0.5)$ & \\
\hline Benign prostatic hyperplasia & $21(8.4)$ & $15(8.2)$ & \\
\hline Other conditions & $70(28)$ & $48(26)$ & \\
\hline
\end{tabular}

Values are presented as numbers, numbers (\%), or means \pm SD. ${ }^{1}$ Number of transfused blood units for each category.

Healthcare System was largely reorganized in order to control the global emergency [2]. This had several consequences for the usual and scheduled clinical management of patients affected by conditions other than SARS$\mathrm{CoV}-2$, including urological diseases $[2,3]$. Indeed, the vast majority of urology departments in Italy faced a consistent reduction of the numbers of ward beds and surgeries due to a significantly lower availability of operating theatres, with a consequent increase in surgical waiting lists $[2,4]$. This scenario translated into the need to prioritize urgent urological conditions over others, and the European Urological Association (EAU) promptly developed guidelines to define priorities during the SARSCoV-2 pandemic [5]. According to these newly revised scientific guidelines, alternative treatments may be offered to patients in order to reduce the overall load of daily visits to the hospital, while also saving surgical slots for oncological high-risk patients in the operating rooms. Besides that, a significant reduction of the number of patients seeking medical help and admitted to the emergency departments (ER) has been observed [2]; one of the reasons for this is patients' fear of facing the risk of SARS$\mathrm{CoV}-2$ contagion. In the end, what really happened was a significant deferment of patient treatments, with the expected negative short- and midterm consequences. The observed significant decrease in elective urological activities may have already had some effects in daily clinical practice. Indeed, while the impact of deferring oncological treatments in terms of patient survival will be evident in the next several months, postponing the treatment of acute conditions - such as hematuria due to either cancer or benign prostatic hyperplasia - may easily translate into immediate consequences for both patients and the healthcare system, including the need for blood transfusions. Therefore, we aimed to investigate the rate of blood transfusions required during the SARS-CoV-2 pandemic at the urology department of 3 academic centers in the north of Italy.

\section{Methods}

We reviewed hospital chart data on the number of blood transfusions required in 3 academic urology units located in the northern part of Italy within the period of March to April 2020. Patients' diagnoses and reasons for transfusion were recorded. Likewise, the total number of admissions to the urology units was also collected, along with the number of surgeries performed throughout the same time frame. As a consequence, we compared these data with those from the same period in 2019 (March to April 2019). We applied descriptive statistics with $\chi^{2}$ and $t$ tests to assess differences between the 2 time periods.

\section{Results}

Table 1 details hospital chart data regarding blood transfusions provided at all centers within the 2 analyzed periods. The number of patients admitted from March to 
April 2020 was approximately one third of the number admitted from March to April 2019 (i.e., 373 vs. 1,119). Similarly, the number of surgeries was significantly lower in 2020 compared to 2019 (242 vs. 938, respectively). However, we recorded almost comparable numbers of blood transfusions between the 2 years of the investigation, with a total of 182 blood units transfused from March to April 2020, compared to 252 from March to April 2019 (Table 1). Of note, the mean number of blood units per admission $( \pm S D)$ was $0.49( \pm 1.62)$ in 2020 , compared to only $0.22( \pm 0.84)$ in $2019(p<0.0001)$. Compared to 2019, from March to April 2020 we observed an increased rate of transfusions due to hematuria (36 vs. 7.9\%; $p<0.0001)$. When looking at the disease underlining each blood transfusion, we observed that bladder cancer (BCa) and kidney cancer were the most common diagnoses in patients receiving blood units in both time periods, followed by benign prostatic hyperplasia and prostate cancer (Table 1). However, from March to April 2020 there was a higher rate of blood units transfused for $\mathrm{BCa}(47 \mathrm{vs}$. $34 \%)$ and a lower rate of transfusions for prostate cancer (0.5 vs. $11 \%)$ compared to March to April 2019 ( $p=$ $0.0002)$.

\section{Discussion/Conclusion}

Despite a consistent decrease in the number of admissions and surgeries performed at the urology units of 3 academic centers, these data show that during the SARS$\mathrm{CoV}-2$ pandemic there was a significant increase in the number of required blood transfusions. It is possible to speculate that this finding could be the consequence of 2 main factors. Firstly, recently patients have been less keen to visit the ER due to lockdown national restriction policies and a diffused fear of contagion. Indeed, on March 9, 2020 , the Italian government issued an ordinance advising patients to avoid visiting the ER and hospitals [6] if not strictly necessary. The delay in seeking help for conditions such as hematuria may have increased the need for blood transfusions at the time of patients' admission to the hospital. Secondly, the current significantly lower availability of operating rooms may have induced physicians to look for more conservative strategies to manage acute and chronic bleeding whenever it was possible, including blood transfusions.

The observed increased use of blood units at our departments should not be considered only as a reflection of the reorganization of the healthcare system in a time of global emergency; it may also have some clinical implica-

Blood Transfusion in Urology during the COVID19 Pandemic tions. Indeed, blood transfusions have been associated with a low but still relevant risk of noninfectious adverse events [7]. If this speculation is true, these may be even more relevant for patients with malignancies; indeed, blood transfusions could lead to worse oncological outcomes due to the effect of transfusion-related immunomodulation, although convincing evidence is still lacking [8]. Indeed, alteration of the regulation of the immune system is a recognized risk factor for a poor prognosis in $\mathrm{BCa}$ [9]. In this context, perioperative blood transfusions have been associated with worse survival rates after surgery for $\mathrm{BCa}[10]$. Likewise, it has been previously shown that perioperative blood transfusions could be associated with acute or chronic renal function deterioration in patients submitted to partial or radical nephrectomy [11]. Lastly, we should consider that the increased need for blood transfusions may not be adequately covered in a time of global blood shortage due to social restrictions affecting blood collection itself [12]. Indeed, a previous report showed that the number of blood donors dropped by $67 \%$ in a region significantly affected by the pandemic in China [13]. Likewise, data showed a $10-30 \%$ drop in donor attendance in the USA [14], leading the US Food and Drug Administration to modify the criteria for regular blood donations in an effort to increase blood availability [15]. In light of these data, a similar shortage of available blood units is likely to also affect Italy [16].

In conclusion, this report shows that conservative strategies, such as blood transfusions, are being employed more frequently to manage urological conditions in the SARS-CoV-2 pandemic, with possible negative consequences both for the patients and the healthcare system. This may be only the tip of the iceberg of what we are going to face in the next few months as a consequence of the impact of SARS-CoV-2 infections on the healthcare system.

\section{Statements of Ethics}

This study was conducted in accordance with the Declaration of Helsinki. All of the patients gave their consent for recording of their clinical data. The analysis of this study did not involve the use of individual patient data; only data on the number of in-hospital procedures carried out during the study period were used for the analysis, without need for local ethical committee approval.

\section{Conflict of Interest Statement}

None. 


\section{Funding Source}

No specific grant from funding agencies in the public, commercial, or not-for-profit sector was received for this research.

\section{Author Contributions}

P. Capogrosso: project development, data analysis, and writing of this work. L. Candela, P. Rossi, C. Guarasci, R. Chianese, L. Santoleri, M. Tassara, F. Muttin, and M. Roscigno: data collection. R. Naspro, A. Salonia, L. Da Pozzo, and G. Carcano: editing of this paper. F. Montorsi: supervision. F. Dehò: project development and editing of this paper.

\section{References}

1 Title N. n.d. http://www.protezionecivile.gov. it/media-comunicazione/comunicati-stam$\mathrm{pa} /$ dettaglio/-/asset_publisher/default/content/coronavirus-la-situazione-dei-contagiin-ita-28 (accessed May 16, 2020).

2 Naspro R, Da Pozzo LF. Urology in the time of corona. Nat Rev Urol. 2020 May; 17(5): 251-3.

3 Morlacco A, Motterle G, Zattoni F. The multifaceted long-term effects of the COVID-19 pandemic on urology. Nat Rev Urol. 2020 Jul; 17(7):365-7.

4 Campi R, Amparore D, Capitanio U, Checcucci E, Salonia A, Fiori C, et al. Assessing the Burden of Nondeferrable Major Uro-oncologic Surgery to Guide Prioritisation Strategies During the COVID-19 Pandemic: Insights from Three Italian High-volume Referral Centres. Eur Urol. 2020 Jul;78(1):11-5.

5 Ribal MJ, Cornford P, Briganti A, Knoll T, Gravas S, Babjuk M, et al.; GORRG Group; EAU Section Offices and the EAU Guidelines Panels. European Association of Urology Guidelines Office Rapid Reaction Group: An Organisation-wide Collaborative Effort to Adapt the European Association of Urology Guidelines Recommendations to the Coronavirus Disease 2019 Era. Eur Urol. 2020 Jul; 78(1):21-8
6 Title N. n.d. http://www.governo.it/it/articolo/firmato-il-dpcm-9-marzo-2020/14276 (accessed May 16, 2020).

7 Carson JL, Triulzi DJ, Ness PM. Indications for and adverse effects of red-cell transfusion. N Engl J Med. 2017 Sep;377(13):1261-72.

8 Cata JP, Wang H, Gottumukkala V, Reuben J, Sessler DI. Inflammatory response, immunosuppression, and cancer recurrence after perioperative blood transfusions. Br J Anaesth. 2013 May;110(5):690-701.

9 Busetto GM, Porreca A, Del Giudice F, Maggi M, D'Agostino D, Romagnoli D, et al. SARSCoV-2 Infection and High-Risk Non-MuscleInvasive Bladder Cancer: Are There Any Common Features? Urol Int. 2020;104(7-8): 510-22.

10 Cata JP, Lasala J, Pratt G, Feng L, Shah JB. Association Between Perioperative Blood Transfusions and Clinical Outcomes in Patients Undergoing Bladder Cancer Surgery: A Systematic Review and Meta-Analysis Study. J Blood Transfus. 2016;2016:1-8.
11 Mühlbauer J, de Gilde J, Mueller-Steinhardt M, Porubsky S, Walach M, Nuhn P, et al. Perioperative Blood Transfusion Is a Predictor of Acute and Chronic Renal Function Deterioration after Partial and Radical Nephrectomy for Renal Cell Carcinoma. Urol Int. 2020; 104(9-10):775-80.

12 Yazer MH, Jackson B, Pagano M, RahimiLevene N, Peer V, Bueno JL, et al. Vox Sanguinis International Forum on Transfusion Services about Response to COVID-19. Vox Sang. 2020 May 8;10.1111/vox.12943.

13 Wang Y, Han W, Pan L, Wang C, Liu Y, Hu W, et al. Impact of COVID-19 on blood centres in Zhejiang province China. Vox Sang. 2020 Apr 29;10.1111/vox.12931.

14 Pagano MB, Hess JR, Tsang HC, Staley E, Gernsheimer T, Sen N, et al. Prepare to adapt: blood supply and transfusion support during the first 2 weeks of the 2019 novel coronavirus (COVID-19) pandemic affecting Washington State. Transfusion. 2020 May;60(5):908-11.

15 Tolich D, Auron M, McCoy K, Dargis M, Quraishy N. Blood management during the COVID-19 pandemic. Cleve Clin J Med. 2020 Aug 7.

16 Franchini M, Farrugia A, Velati C, Zanetti A, Romanò L, Grazzini G, et al. The impact of the SARS-CoV-2 outbreak on the safety and availability of blood transfusions in Italy. Vox Sang. 2020 Apr 2;10.1111/vox.12928. 